\title{
Modelo de retroalimentação do processo de projeto a partir de informações sobre satisfação de clientes
}

\author{
Model for feeding back client satisfaction information \\ into the design process
}

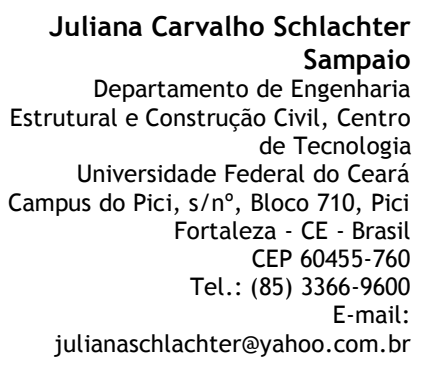

Neliza Maria Silva e Romcy

Departamento de Engenharia Estrutural e Construção Civil, Centro de Tecnologia

Universidade Federal do Ceará

E-mail: nelizaromcy@gmail.com

Paula Lima Sombra Departamento de Engenharia Estrutural e Construção Civil, Centro de Tecnologia Universidade Federal do Ceará E-mail: paulasombra@yahoo.com.br

José de Paula Barros Neto

Departamento de Engenharia Estrutural e Construção Civil, Centro
de Tecnologia

Universidade Federal do Ceará

E-mail: jpbarros@ufc.br

Recebido em 01/08/11 Aceito em 16/12/11

\section{Juliana Carvalho Schlachter Sampaio \\ Neliza Maria Silva e Romcy \\ Paula Lima Sombra \\ José de Paula Barros Neto}

Resumo

$\Delta$

lguns incorporadores imobiliários, para ter uma retroalimentação acerca de seus empreendimentos, têm coletados dados em avaliações de satisfação de clientes. Porém, com frequiência estes dados não são utilizados sistematicamente na retroalimentação durante a gestão de novos projetos. A literatura aponta a importância uma efetiva retro-alimentação a partir destas avaliações, pois, dessa forma, os projetistas poderão gerar mais valor para o usuário final. Esta pesquisa tem como objetivo propor um modelo teórico de análise dos dados oriundos de avaliações de satisfação, para aumentar a eficácia da retroalimentação do processo de projeto. A pesquisa teve um caráter qualitativo e dividiu-se em quatro etapas: análise das ferramentas; adaptação dessas ferramentas; teste do modelo; e aplicação prática do modelo.

Palavras-chave: Ferramentas. Projeto. Retroalimentação. Valor. Satisfação.

\section{Abstract}

Some buiding developers, in order to have a feedback of their projects, have used collected data in client satisfaction evaluations. However, such data are rarely used in a systematic way for feeding back the management of new projects. The literature points out the importance of an effective feedback from those evaluations, so that designers can generate more value for the final client. The objective of this research work is to propose a theoretical model for processing data collected in client satisfaction evaluations, with the aim of improving the effectiveness of the feedback into the design process. This investigation had a qualitative character, and was divided into main stages: analysis of tools, adaptation of tools, model testing, and model practical application.

Keywords: Tools. Design. Feedback. Value. Satisfaction. 


\section{Introdução}

Com o intuito de obter uma retroalimentação dos usuários finais acerca de empreendimentos já entregues, alguns incorporadores têm recorrido a avaliações de satisfação. Nesse sentido, algumas pesquisas relacionadas com satisfação do cliente foram realizadas para compreender suas necessidades (EGEMEN; MOHAMED, 2006; TANG; LU; CHAN, 2004). Enquanto a literatura aponta para a importância da incorporação dados advindos das avaliações de satisfação (ORNSTEIN, 2008), observa-se que os dados coletados não têm sido utilizados sistematicamente na retroalimentação desse processo.

Sobretudo em pesquisas com foco em habitação de interesse social, a percepção de satisfação dos usuários pode estar condicionada a uma situação anterior de moradia, distorcendo o índice de satisfação com o imóvel atual. Assim, destacam-se algumas pesquisas que abordam o conceito de valor para o usuário (LIMA, 2011; MAIA; LIMA; BARROS NETO, 2011).

Em relação ao projeto, verifica-se sua importância sobre o ciclo de vida dos produtos, incluindo a construção e o uso. A definição do programa arquitetônico torna-se, portanto, importante para o processo geral. Moreira e Kowaltowski (2009) destacam que, por anteceder o projeto, este se inicia com o levantamento das informações relativas ao cliente e ao contexto, e busca descrever as condições nas quais o projeto vai operar e o problema ao qual a edificação projetada responderá. Tilley (2005) destaca que o programa deve ser flexível e dinâmico, e que deve estar disponível para alterações que forem necessárias durante todo o processo de projeto e construção, já que as necessidades dos clientes podem mudar ao longo do tempo e alterações podem vir a agregar mais valor para o cliente.

Com o intuito de possibilitar a incorporação das necessidades dos clientes de uma maneira sistematizada e auxiliar na atividade exploratória das etapas iniciais do projeto, algumas ferramentas de apoio à tomada de decisão podem ser utilizadas.

O objetivo geral deste artigo é, portanto, propor um modelo teórico de análise dos dados oriundos de avaliações de satisfação que auxilie a retroalimentação do processo de projeto, a fim de possibilitar a geração de valor para os clientes.

Os objetivos da pesquisa são analisar a viabilidade de utilização das ferramentas de apoio à tomada de decisão no processo de projeto a partir da compilação dos aspectos positivos e negativos das ferramentas; adaptar as ferramentas para as especificidades da construção civil, de forma a sistematizar a retroalimentação do processo de projeto, através da análise e da eleição dos atributos aplicáveis de cada ferramenta; testar o modelo proposto por meio da aplicação junto a arquitetos e engenheiros civis; e aplicar o modelo de retroalimentação em uma aplicação prática, que possibilite a análise e a discussão de sua viabilidade, vantagens e possíveis limitações, além da proposição de alterações para seu aperfeiçoamento.

Vale ressaltar que a apresentação dos resultados da primeira etapa metodológica desta pesquisa, relativa ao primeiro objetivo supracitado, foi realizada por Sampaio, Lima e Baros Neto (2010).

\section{Referencial teórico}

\section{Processo de projeto}

O processo de projeto, segundo Tilley (2005), é uma atividade mental que tem como produto ideias documentadas em meio físico ou eletrônico, o que facilita a comunicação para outros envolvidos no processo. O projeto, por sua vez, ocorre ao longo de algumas etapas, que vão do programa arquitetônico ao projeto executivo. Verifica-se que esse processo envolve uma interação e um compromisso entre um grupo de stakeholders, os quais incluem o cliente, os usuários finais, os projetistas, os empreiteiros e os fornecedores, entre outros (KÄRNA; JUNNONEN, 2005). A natureza do processo de projeto pode, portanto, ser considerada complexa.

Whelton e Ballard (2002) destacam alguns problemas que influenciam negativamente o processo de projeto, como a falta de compartilhamento das decisões tomadas, os fatores sociopolíticos que dominam a tomada de decisão e o ineficiente processamento das informações. Koskela, Huovila e Leinonen (2002) apontam, ainda, a inexistência de um planejamento sistemático do projeto e o gerenciamento ineficaz do valor a partir do ponto de vista do cliente.

Diante desse contexto, a retroalimentação do processo, com informações provenientes do uso de empreendimentos já entregues aos usuários, referese a uma das alterações necessárias que dizem respeito às relações do projeto com as demais atividades inseridas no processo de desenvolvimento de produtos da indústria da construção civil (MELHADO; AGOPYAN, 1995). Nesse caso, as avaliações pós-ocupação podem comportar-se como banco de dados retroalimentadores do processo de projeto. 


\section{Ferramentas de apoio à tomada de decisão}

Quatro ferramentas apresentadas por Sampaio, Lima e Barros Neto (2010) mostraram-se passíveis de ser utilizadas na retroalimentação do processo de projeto. A primeira delas, o processo de análise hierárquico (AHP), utiliza uma metodologia de comparação quantitativa que ajuda a verificar a relação entre alternativas qualitativas a serem consideradas na decisão a ser tomada (GASS, 1985). Essa ferramenta pode, portanto, tornar o processo de seleção, ordenamento e julgamento transparente (CARVALHO; SPOSTO, 2007) e permite que o sistema de atribuição de pesos torne o problema mais gerenciável.

Quanto ao projeto axiomático (AD), ele foi desenvolvido para auxiliar na identificação dos problemas existentes no processo de projeto que geravam soluções menos eficazes (MONICE; PETRECHE, 2004). Sua utilização dá-se a partir da premissa de que existem princípios generalizáveis definidores do processo de projeto, e a questão de projeto é definida a partir de dois questionamentos básicos: "o que nós (clientes e projetistas) queremos" e "como iremos conseguir" (MONICE; PETRECHE, 2004). Segundo Yang e Zhang (2000), a AD ajuda a eliminar as tentativas e erros do processo de projeto convencional e a estruturar e entender melhor os problemas de projeto.

Já a teoria da solução inventiva de problemas (TRIZ) foi idealizada por Altshuller mediante a análise dos processos envolvidos na obtenção das soluções criativas contidas nas patentes (CARVALHO; BACK, 2001). A TRIZ consiste na reestruturação de um problema de projeto específico em um problema genérico cuja solução tenha princípios referenciais consolidados. A mais conhecida das metodologias que compõem a TRIZ associa-se ao método dos princípios inventivos, os quais representam sugestões de possíveis soluções para determinado problema (CARVALHO; BACK 2001). A ferramenta auxilia os projetistas no processo de concepção de produtos, evitando o método convencional, baseado no know how e na "tentativa e erro", e resolvendo os problemas de uma maneira criativa (YANG; ZHANG, 2000).

Por último, o desdobramento da função qualidade (QFD) é uma ferramenta utilizada para aumentar o nível de satisfação dos clientes. Segundo DelgadoHernandez, Bampton e Aspinwall (2007), o principal objetivo do QFD é ajudar a identificar e a priorizar as necessidades dos clientes, e a transformá-las em características do produto. A ferramenta é composta de quatro matrizes, que desdobram as necessidades dos clientes em requisitos de projeto, os quais originam as características do componente, que são transformados em operações de fabricação e definem os requisitos de produção (EUREKA; RYAN, 1992). O QFD auxilia na tradução das necessidades dos clientes em atributos de projeto e, portanto, relaciona-se diretamente com a geração de valor.

\section{Metodologia}

Esta pesquisa classifica-se como qualitativa e exploratória, uma vez que os dados provêm do ambiente natural, e busca aprofundar a análise de um assunto pouco discutido na literatura, o uso de ferramentas de apoio à tomada de decisão no contexto da retroalimentação do processo de projeto. Também é uma pesquisa bibliográfica que convergiu para a proposição de um modelo teórico de auxílio à retroalimentação do processo de projeto.

A fim de verificar o processo de aplicação desse modelo e de refinar sua primeira versão, realizouse um pré-teste com engenheiros e arquitetos de um grupo de pesquisa. Foi feita uma pesquisa documental relativa às avaliações de satisfação escolhidas para ser base de dados do processo de aplicação da segunda versão do modelo. Em seguida, um grupo focal foi realizado com arquitetos e engenheiros civis atuantes no mercado da construção civil de Fortaleza. Numa situação supostamente real, a aplicação da segunda versão do modelo possibilitou verificar como os projetistas enxergam a utilização das ferramentas analisadas. A partir desses dados, essa versão do modelo foi analisada, e o modelo teórico final foi proposto. Por último, realizou-se uma aplicação prática do modelo junto a dois empreendimentos.

O delineamento desta pesquisa compõe-se de quatro etapas, conforme pode ser observado na Figura 1. 


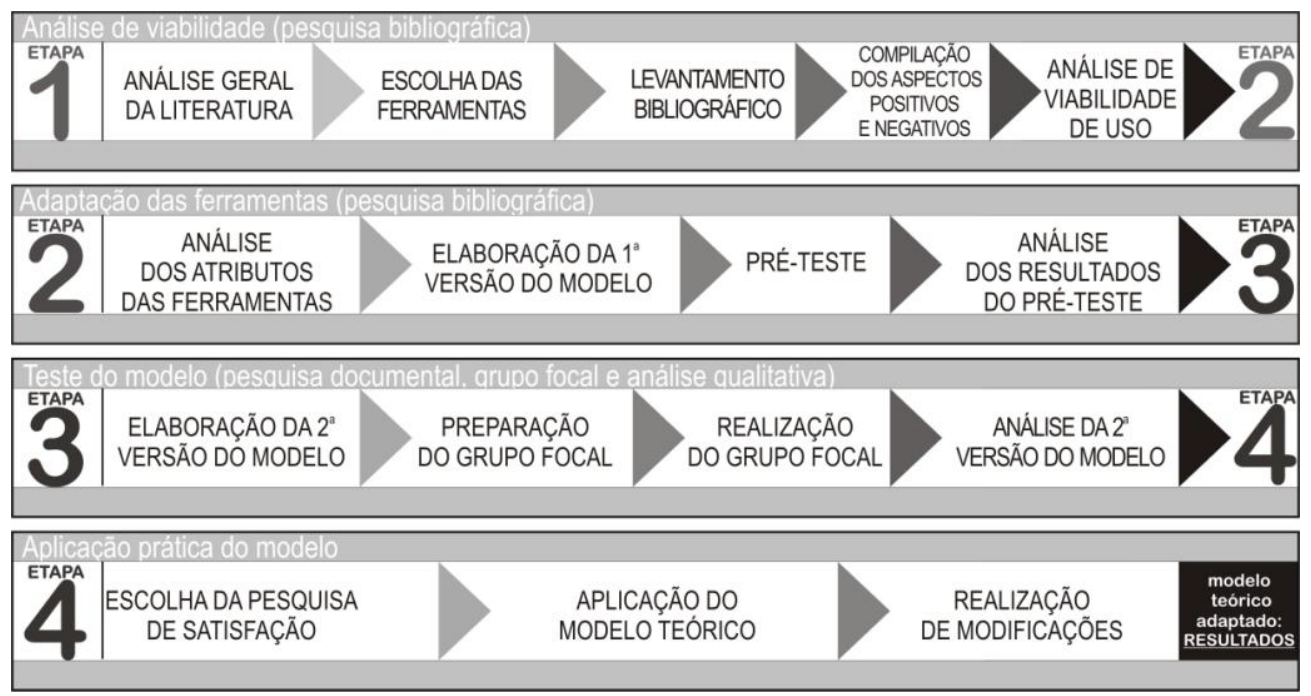

Figura 1 - Delineamento da pesquisa

$\mathrm{Na}$ primeira etapa, as ferramentas de apoio à tomada de decisão foram analisadas. Para a escolha das ferramentas, realizou-se uma análise geral da literatura acerca do processo de projeto e do desenvolvimento de produtos. Considerou-se a existência de discussões acerca das ferramentas em publicações de programas de pós-graduação de universidades brasileiras, especificamente no contexto da arquitetura e da construção civil. Dessa forma, pôde-se verificar a viabilidade de uso das ferramentas no contexto em que se insere esta pesquisa. Em seguida, foi realizado um levantamento bibliográfico específico sobre cada ferramenta, o que permitiu a compilação dos aspectos positivos (vantagens de uso) e negativos (limitações de uso) de cada ferramenta. Por último, verificou-se a análise de viabilidade de uso das ferramentas escolhidas em função de seu uso em pesquisas brasileiras; da adequação dos conceitos e objetivos de utilização das ferramentas ao contexto da construção civil; da relação entre os aspectos positivos das ferramentas e a geração de valor; e da possibilidade de minimização dos aspectos negativos das ferramentas.

$\mathrm{Na}$ segunda etapa, as ferramentas foram adaptadas para as especificidades da construção civil, de forma a sistematizar a retroalimentação do processo de projeto, compondo uma primeira versão do modelo. Com base na análise e na eleição dos atributos aplicáveis de cada uma das ferramentas analisadas, dentro do contexto específico da construção civil, foram avaliadas a valorização dos aspectos positivos das ferramentas, a minimização ou a eliminação dos aspectos negativos, bem como a integração teórica das ferramentas dentro de um único modelo. Em seguida, a fim de se verificar a constituição dessa primeira versão do modelo, foi realizado o pré- teste $^{1}$. Finalmente, as críticas tecidas sobre o modelo e os insights gerados durante o pré-teste foram compilados.

Na terceira etapa, o modelo teórico de auxílio à retroalimentação do processo de projeto foi testado. A segunda versão do modelo foi elaborada a partir das sugestões e das críticas resultantes do pré-teste. Para analisar essa versão do modelo, o grupo focal ${ }^{2}$ foi adotado para testar os passos que o compõem. Deste participaram quatro engenheiros e seis arquitetos que tinham alguma relação com empreendimentos de interesse social. Antes da realização do grupo focal, contudo, realizou-se uma pesquisa documental relacionada à avaliação de satisfação selecionada. Para finalizar, essa versão do modelo foi analisada qualitativamente mediante a preparação dos dados do grupo focal, da codificação e categorização temática e da análise comparativa. $\mathrm{O}$ modelo proposto foi avaliado, e sua versão final, consolidada.

Por fim, a aplicação prática do modelo foi realizada a partir de uma pesquisa de satisfação com moradores de dois empreendimentos imobiliários voltados para o público de classe média alta. Nessa etapa, surgiram desafios que trouxeram a necessidade de adaptação de alguns

\footnotetext{
${ }^{1}$ Os dados utilizados no pré-teste resultaram de uma avaliação de satisfação realizada pelo grupo de pesquisa com moradores de um empreendimento multifamiliar.

${ }^{2}$ Para o grupo focal, foi utilizada uma avaliação de satisfação coordenada pelo mesmo grupo de pesquisa com três empreendimentos do Programa de Arrendamento Residencial/Caixa Econômica Federal (PAR/CEF), fruto de uma pesquisa financiada pela Financiadora de Estudos e Projetos (Finep) através do Fundo Verde Amarelo/Habitare. Essa

avaliação insere-se no projeto de pesquisa Gerenciamento de Requisitos e Melhoria da Qualidade na Habitação de Interesse Social (GERENCIAMENTO..., 2008).
} 
aspectos do modelo teórico, possibilitando a proposta de melhorias para ele.

\section{Análise das ferramentas}

Conforme relatado anteriormente, a apresentação da primeira etapa desta pesquisa foi abordada por Sampaio, Lima e Barros Neto (2010). Concluiu-se que as quatro ferramentas (AHP, AD, TRIZ e QFD) são passíveis de ser utilizadas no processo de projeto da construção civil. O AHP ajuda a determinar a priorização entre alternativas. Já a AD e o QFD auxiliam no desdobramento das necessidades do cliente em características de projeto e gerenciam os trade offs que possam ocorrer nesse processo. E a TRIZ aponta para possibilidades de soluções de projeto.

\section{Adaptação das ferramentas}

Uma vez que o modelo teórico deve comportar-se como um auxílio para a retroalimentação do processo de projeto, presume-se que os dados a serem inseridos no processo referem-se às necessidades dos clientes que foram consideradas insatisfatórias. Estas, portanto, devem ser transformadas em novos parâmetros de projeto, os quais serão incorporados no processo de desenvolvimento de novos produtos. A utilização das ferramentas está associada a essa condição.

Verificou-se que o AHP adapta-se ao modelo teórico proposto, uma vez que possibilita a comparação pareada entre alternativas em função de critérios específicos definidos pelos avaliadores. Essa ferramenta, portanto, pode auxiliar na priorização das necessidades dos clientes ou dos parâmetros de projeto, os dados trabalhados no modelo teórico.

Em relação aos domínios que compõem a $\mathrm{AD}$, foram considerados o domínio do cliente, correspondente a suas necessidades, o domínio funcional, correspondente aos requisitos funcionais que atendem a essas necessidades, e o domínio físico, o qual se refere aos parâmetros de projeto que satisfazem os requisitos anteriores.

Quanto ao QFD, o objeto de análise foi a matriz da casa da qualidade, uma vez que se relaciona com as primeiras fases do processo de projeto. Julgouse importante a verificação das interferências que existem entre as necessidades dos clientes e os requisitos de projeto.
Quanto à TRIZ, averiguou-se que o modelo teórico pode fazer uso dos princípios inventivos de uma forma direta, a partir da correspondência entre eles e os parâmetros de projeto a serem propostos.

\section{Proposição do modelo}

Para alcançar a proposição do modelo teórico, foram elaboradas duas versões preliminares do modelo (Figura 2).

\section{Primeira versão do modelo}

A primeira versão do modelo teórico compõe-se por cinco passos, propostos de forma a ser realizados sequencialmente e a possibilitar gerar uma discussão sistematizada acerca das necessidades dos clientes logo na primeira etapa do processo de projeto (concepção do produto):

1 Definição das necessidades dos clientes a partir dos resultados de avaliações de satisfação.

2 Desdobramento das necessidades dos clientes em primárias, secundárias e terciárias, utilizando o diagrama de afinidades.

3 Transformação das necessidades insatisfatórias em parâmetros de projeto através do auxílio da AD e da TRIZ.

4 Priorização dos parâmetros de projeto com o auxílio do AHP.

5 Avaliação das interferências entre as necessidades dos clientes e os parâmetros de projeto através da Casa da Qualidade.

Como produto final, esta discussão, abalizada pelo roteiro supracitado, resulta em um documento formal contendo as necessidades dos clientes e as soluções de projeto sugeridas pelos projetistas, bem como as interferências entre elas. Este documento, portanto, fica disponível aos participantes do processo de projeto e serve como base de dados para projetos futuros com características semelhantes.

A partir da aplicação do modelo no pré-teste, algumas alterações foram realizadas. As principais referem-se à exclusão da ferramenta TRIZ, em função do tempo demandado para o conhecimento acerca dos princípios inventivos, e à inversão dos passos 3 e 4, devido à importância, por um lado, de se considerarem todos os parâmetros de projeto, e, por outro, de priorizar as necessidades insatisfatórias quando elas existirem em grande número. 


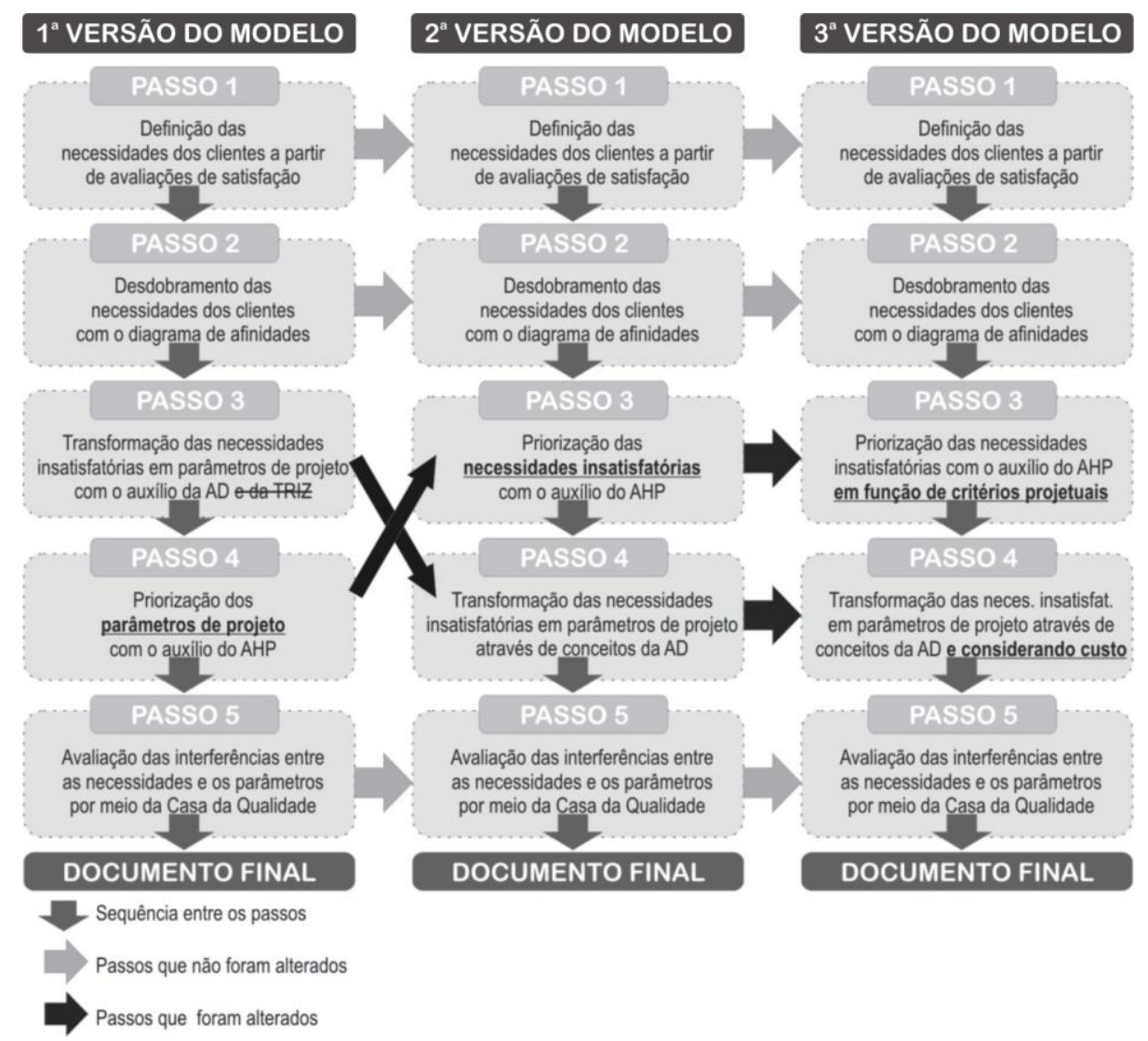

Figura 2 - Relação entre as três versões do modelo Fonte: Sampaio (2010).

\section{Segunda versão do modelo}

A nova sequência de realização dos passos é composta do roteiro a seguir:

1 Mantém-se igual à versão 1.

2 Mantém-se igual à versão 1.

3 Priorização das necessidades insatisfatórias com o auxílio do AHP.

4 Transformação das necessidades insatisfatórias em parâmetros de projeto através de conceitos da AD.

5 Mantém-se igual à versão 1.

Esta versão do modelo foi empregada durante o grupo focal. Os três primeiros passos foram realizados antes do grupo focal, como uma atividade de preparação dos dados para discussão junto aos projetistas. Já os dois últimos passos foram realizados por dois grupos distintos.

\section{Definição das necessidades dos clientes (Figura 3)}

As necessidades dos clientes foram definidas e listadas a partir do relatório final de uma avaliação de satisfação feita com três empreendimentos. Para cada um deles, foram indicados o nível de satisfação (baseado na porcentagem das respostas) e as considerações existentes acerca das insatisfações. O critério de classificação das necessidades foi:

(a) o item do questionário cujo somatório de "muito satisfeito" e "satisfeito" fosse superior a $50 \%$ das respostas dos entrevistados foi considerado necessidade satisfatória;

(b) o item citado pelos respondentes como um dos cinco itens de que eles mais gostaram no apartamento ou no condomínio (item positivo), porém que não tenha sido citado como item negativo ou não tenha sido considerado insatisfatório ou equilibrado em relação aos itens do questionário, foi considerado necessidade satisfatória;

(c) o item cujo somatório de "muito insatisfeito" e "insatisfeito" fosse igual ao somatório de "muito satisfeito" e "satisfeito" foi considerado necessidade neutra;

(d) o item citado pelos respondentes tanto como um dos cinco itens de que mais gostou no apartamento ou no condomínio (item positivo) 
quanto como um dos que menos gostou (item negativo) foi considerado necessidade neutra;

(e) o item cujo somatório de "muito insatisfeito" e "insatisfeito" em pelo menos um dos empreendimentos fosse superior a $50 \%$ das respostas dos entrevistados foi considerado necessidade insatisfatória; e

(f) o item citado pelos respondentes apenas como um dos cinco itens de que menos gostou no apartamento ou no condomínio (item negativo) foi considerado necessidade insatisfatória.

As necessidades foram classificadas conforme se apresenta no Quadro 1.

\section{Desdobramento das necessidades dos clientes (Figura 4)}

Todas as necessidades listadas no item anterior (terciárias) foram escritas em cartões de dados com cores específicas (verde para as necessidades satisfatórias, amarela para as neutras, e magenta para as insatisfatórias). Os cartões de dados foram agrupados de acordo com suas afinidades. As 53 necessidades geraram 19 grupos de afinidade, as necessidades secundárias. Por último, os grupos de afinidade foram reunidos em grupos mais abrangentes, o que totalizou 10 necessidades primárias (Figura 5). Esse diagrama de afinidades, resultante da aplicação dos passos 1 e 2, foi apresentado durante o grupo focal.

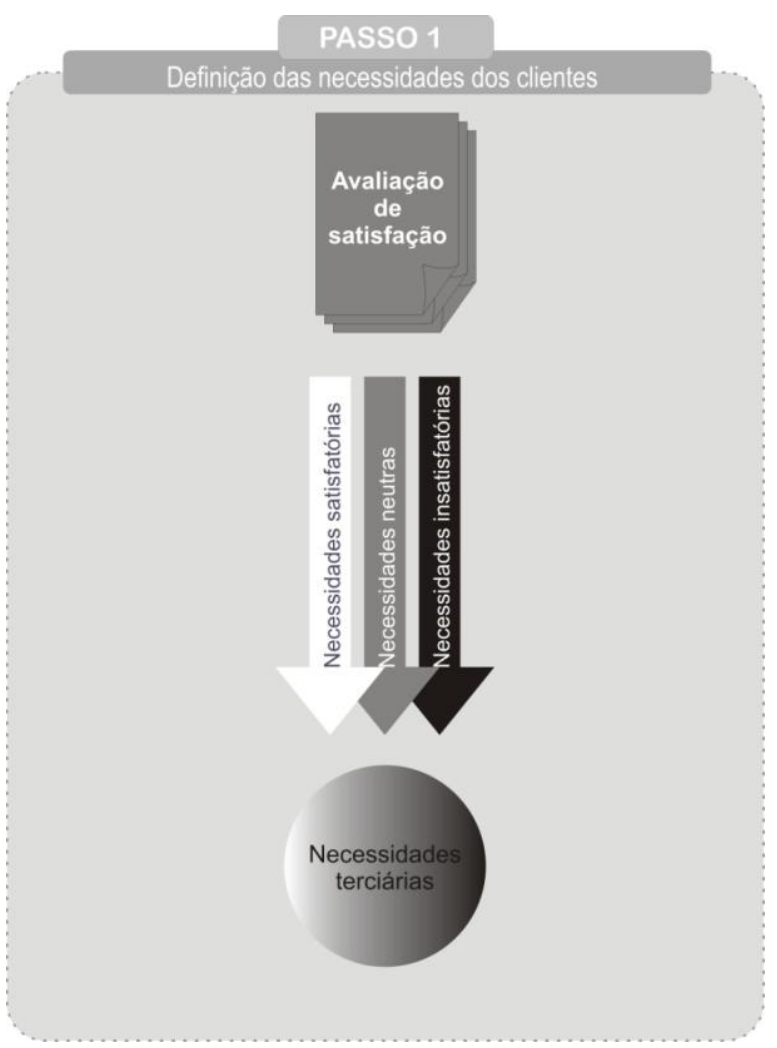

Figura 3 - Passo 1 do modelo teórico

Fonte: Sampaio (2010). 


\begin{tabular}{|c|c|c|}
\hline \multicolumn{3}{|c|}{ NECESSIDADES } \\
\hline SATISFATÓRIAS & NEUTRAS & INSATISFATÓRIAS \\
\hline Estrutura física & Áreas condominiais como um todo & Salão de festas \\
\hline Aspectos da u.h. & Apto. como um todo & Guarita (adeq./uso) \\
\hline Escadas e corredores & Praça infantil & Cozinha/Á.serv. (adeq./uso) \\
\hline Dormitórios (adeq./uso) & Área verde & Nivel de ruído \\
\hline Estar/jantar (adeq./uso) & Entrada do bloco & Iluminação externa \\
\hline Banheiros (adeq./uso) & Estacionamento & Temperatura e ventilação \\
\hline Iluminação natural & Manutenção & Material das portas \\
\hline Aparência do condomínio & Limpeza & Qual. das fechaduras \\
\hline Funcionamento das portas & Aparência externa & Qual. das louças sanitárias \\
\hline Material das janelas & Organização & Qual. dos metais sanitários \\
\hline Funcionamento das janelas & & Drenagem e esgotamento \\
\hline Funcionamento das inst. elétricas & & Parede dormitórios, estar/jantar \\
\hline Quant. de pontos elétricos & & Segurança do bloco \\
\hline Localiz. dos pontos elétricos & & $\begin{array}{l}\text { Privacidade } \\
\end{array}$ \\
\hline \multicolumn{3}{|l|}{ Funcionamento das inst. hidros. } \\
\hline \multicolumn{3}{|l|}{ Localiz. dos pontos das inst. hidros. } \\
\hline \multicolumn{3}{|l|}{ Quant. dos pontos das inst. hidros. } \\
\hline \multicolumn{3}{|l|}{ Impermeabilização } \\
\hline \multicolumn{3}{|l|}{ Teto dormitórios, estar/jantar } \\
\hline \multicolumn{3}{|l|}{ Teto banheiro, cozinha/Ár.serv. } \\
\hline \multicolumn{3}{|l|}{$\begin{array}{c}\text { Parede banheiro, cozinha/Ár.serv. } \\
\text { Piso estar/jantar }\end{array}$} \\
\hline Piso estar/jantar & & \\
\hline \multicolumn{3}{|l|}{ Piso dormitórios } \\
\hline \multicolumn{3}{|l|}{ Piso banheiro, cozinha/Ár. serv. } \\
\hline \multicolumn{3}{|l|}{ Localização } \\
\hline \multicolumn{3}{|l|}{ Serviços públicos } \\
\hline PAR & & \\
\hline \multicolumn{3}{|l|}{ Tranquilidade } \\
\hline Vida em condomínio & & \\
\hline
\end{tabular}

Quadro 1 - Classificação das necessidades dos clientes

Fonte: Sampaio (2010).

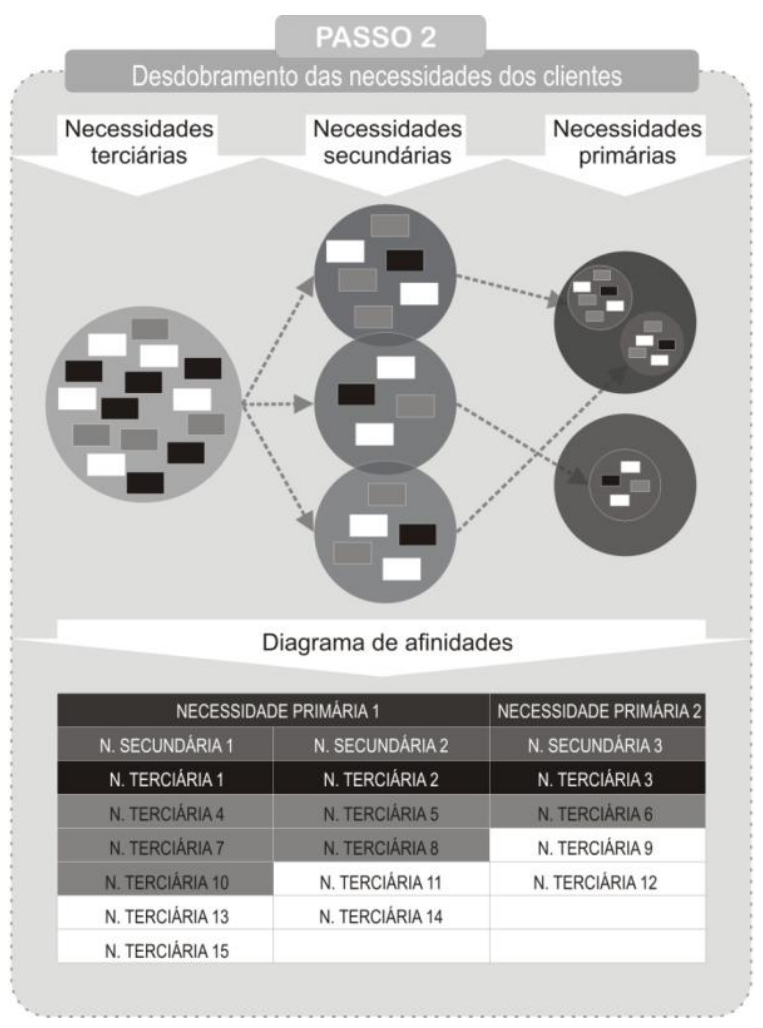

Figura 4 - Passo 2 do modelo teórico

Fonte: Sampaio (2010).

136 Sampaio, J. C. S.; Silva e Romcy, N. M.; Sombra, P. L.; Barros Neto, J. de P. 


\begin{tabular}{|c|c|c|c|c|c|c|c|}
\hline & & Aspectos da u.h. & Estrutura fisica & $\begin{array}{l}\text { Apto. como um } \\
\text { todo }\end{array}$ & $\begin{array}{c}\text { Areas } \\
\text { condominiais } \\
\text { como um todo }\end{array}$ & $\begin{array}{c}\text { PROJETO } \\
\text { ARQUITETÔNICO }\end{array}$ & $\begin{array}{c}\text { PROJETO } \\
\text { ARQUITETÓNICO }\end{array}$ \\
\hline & & & Área verde & Praça infantil & Salão de festas & LAZER & \multirow{2}{*}{ ÁREA COMUM } \\
\hline & & $\begin{array}{l}\text { Escadas e } \\
\text { corredores }\end{array}$ & $\begin{array}{l}\text { Estaciona- } \\
\text { mento }\end{array}$ & Entrada do bloco & $\begin{array}{c}\text { Guarita } \\
\text { (adeq.Juso) }\end{array}$ & SERMÇOS & \\
\hline & & & & $\begin{array}{l}\text { Estarjjantar } \\
\text { (adeq./uso) }\end{array}$ & $\begin{array}{l}\text { Dormitórios } \\
\text { (adeq./uso) }\end{array}$ & ÁREA SECAS & \multirow{2}{*}{$\begin{array}{c}\text { UNIDADE } \\
\text { HABITACIONAL }\end{array}$} \\
\hline & & & & $\begin{array}{l}\text { Banheiros } \\
\text { (adeq./uso) }\end{array}$ & $\begin{array}{c}\text { Cozinha/Áserv. } \\
\text { (adeq./uso) }\end{array}$ & $\begin{array}{c}\text { ÁREAS } \\
\text { MOLHADAS }\end{array}$ & \\
\hline & & & & & Nivel de ruido & ACÚSTICO & \multirow{3}{*}{$\begin{array}{l}\text { CONFORTO } \\
\text { AMBIENTAL }\end{array}$} \\
\hline & & & & |lluminação natural| & $\begin{array}{l}\text { Iluminação } \\
\text { externa }\end{array}$ & LUMINICO & \\
\hline & & & & & $\begin{array}{l}\text { Temperatura e } \\
\text { ventilação }\end{array}$ & TÉRMICO & \\
\hline & $\begin{array}{l}\text { Aparência do } \\
\text { condominio }\end{array}$ & Organização & $\begin{array}{l}\text { Aparência } \\
\text { externa }\end{array}$ & Limpeza & Manutenção & ESTÉTICA & ESTÉTICA \\
\hline & & & $\begin{array}{l}\text { Funcionamento } \\
\text { das portas }\end{array}$ & $\begin{array}{l}\text { Qual. das } \\
\text { fechaduras }\end{array}$ & $\begin{array}{c}\text { Material das } \\
\text { portas }\end{array}$ & PORTAS & \multirow{2}{*}{ ESQUADRIAS } \\
\hline & & & & $\begin{array}{c}\text { Funcionamento } \\
\text { das janelas }\end{array}$ & $\begin{array}{l}\text { Material das } \\
\text { janelas }\end{array}$ & JANELAS & \\
\hline & & & $\begin{array}{l}\text { Localiz. dos } \\
\text { pontos elétricos }\end{array}$ & $\begin{array}{c}\text { Quant. de pontos } \\
\text { elétricos }\end{array}$ & $\begin{array}{l}\text { Funcionamento } \\
\text { das inst. elétricas }\end{array}$ & ELĖTRICAS & \\
\hline \multirow[t]{7}{*}{$\begin{array}{l}\text { Impermeabi- } \\
\text { lização }\end{array}$} & $\begin{array}{l}\text { Quant. dos } \\
\text { pontos das inst. } \\
\text { hidros. }\end{array}$ & $\begin{array}{l}\text { Localiz. dos } \\
\text { pontos das inst. } \\
\text { hidros. }\end{array}$ & $\begin{array}{l}\text { Funcionamento } \\
\text { das inst. hidros. }\end{array}$ & $\begin{array}{c}\text { Qual. dos metais } \\
\text { sanitários }\end{array}$ & $\begin{array}{c}\text { Qual. das louças } \\
\text { sanitárias }\end{array}$ & HIDRO SANITARIAS & INSTALAÇÖES \\
\hline & & & & & $\begin{array}{l}\text { Drenagem e } \\
\text { esgotamento }\end{array}$ & SANEAMENTO & \\
\hline & & & & $\begin{array}{c}\text { Banheiro, } \\
\text { cozinhal } \\
\text { à.serv. }\end{array}$ & $\begin{array}{l}\text { Dormitórios, } \\
\text { estarijantar }\end{array}$ & TETO & \multirow{3}{*}{$\begin{array}{l}\text { ACABAMENTOI } \\
\text { MATERIAIS }\end{array}$} \\
\hline & & & & $\begin{array}{c}\text { Banheiro, } \\
\text { cozinhal } \\
\text { à.serv. }\end{array}$ & $\begin{array}{l}\text { Dormitòrios, } \\
\text { estarijantar }\end{array}$ & PAREDE & \\
\hline & & & $\begin{array}{l}\text { Banheiro, } \\
\text { cozinhal } \\
\text { à. serv. }\end{array}$ & Dormitórios & Estarijantar & PISO & \\
\hline & & PAR & Serviços públicos & Localização & $\begin{array}{l}\text { Segurança do } \\
\text { bloco }\end{array}$ & CONDICIONANTES & $\begin{array}{l}\text { CONDICIONANTES } \\
\text { CONTEXTUAIS }\end{array}$ \\
\hline & & & $\begin{array}{l}\text { Vida em } \\
\text { condominio }\end{array}$ & Tranquilidade & Privacidade & VARIÁVEIS & $\begin{array}{c}\text { VARIÁVEIS } \\
\text { COMPORTAMENTAIS }\end{array}$ \\
\hline
\end{tabular}

Figura 5 - Diagrama de necessidades

Fonte: Sampaio (2010).

\section{Priorização das necessidades insatisfatórias (Figura 6)}

Uma vez que foram encontradas 14 necessidades terciárias insatisfatórias, as quais correspondem a 12 grupos de afinidade, esse passo compreendeu a priorização das necessidades secundárias insatisfatórias com o auxílio do AHP. Nesse caso, definiu-se que os critérios (atributos) de priorização seriam: (a) quantidade de citações: em quantos empreendimentos a necessidade havia sido considerada insatisfatória ${ }^{3}$;

(b) existência de justificativa: se havia dados disponíveis que qualificavam a necessidade como insatisfatória ${ }^{4}$ e

\footnotetext{
${ }^{3}$ Se a necessidade tivesse sido considerada insatisfatória em todos os empreendimentos, ela era considerada um fator crítico, já que se repetia em todos os projetos.

${ }^{4} \mathrm{O}$ questionário utilizado para a avaliação de satisfação não tornava claro, em todos os casos, o motivo de aquela necessidade ter sido considerada insatisfatória, porém algumas justificativas eram verificadas a partir das questões abertas. Portanto, as necessidades insatisfatórias justificadas
} 
(c) interferência em outros grupos de afinidade: se, de antemão, a necessidade terciária insatisfatória já apresentava relação negativa com outras necessidades 5 .

Assim, através da primeira comparação realizada com a ferramenta $\mathrm{AHP}^{6}$, concluiu-se que o critério "quantidade de citações" seria considerado o mais importante para a priorização. Já o critério "interferência em outros grupos de afinidade" foi considerado o menos importante (Quadro 2). Nesse caso, sendo a "quantidade de citações" moderadamente mais importante do que a "existência de justificativa" (5) e bem mais importante do que "interferência em outros grupos de afinidade" $(7)^{7}$, o valor de $\pi$ citação, por exemplo, de acordo com a equação $1^{8}$, foi: $\pi$ citação $=5 \times 7=35$.

Já o significado geométrico correspondente da citação, P, a partir da aplicação da equação 2 , foi:

$P$ citação $=3 \sqrt{ } 35=3,272$.

Por último, a composição de prioridade hierárquica da citação, $\mathrm{p}$, resultante da equação 3 , foi: $\mathrm{p}$ citação $=3,272 /(3,272+0,854+0,362)=0,73$.

Em seguida, foram realizadas comparações pareadas entre as necessidades insatisfatórias em função de cada um dos critérios definidos anteriormente. No caso do critério "citação", foi verificado se uma necessidade havia sido mais citada do que a outra. Quando o número de empreendimentos em que duas necessidades haviam sido citadas era igual, era atribuído o valor 1; quando havia uma diferença de um empreendimento $^{9}$, era atribuído o valor 5; e quando havia uma diferença de dois empreendimentos ${ }^{10}$, era atribuído o valor 9 (Quadro 3). Em relação à comparação entre a necessidade "guarita" e a necessidade "salão de

disponibilizavam mais dados para a discussão junto aos projetistas.

${ }^{5} \mathrm{O}$ fato de uma necessidade insatisfatória influenciar negativamente em outras necessidades era considerado indesejado.

${ }^{6}$ A primeira comparação realizada refere-se à comparação dos atributos em relação ao objetivo de priorizar as necessidades insatisfatórias

${ }^{7} 0$ valor 1 indica igualmente importante; 3 , pouco mais importante; 5 , moderadamente mais importante; 7 , bem mais importante; e 9, muito mais importante.

${ }^{8}$ A forma de utilização das Equações 1, 2, 3 e 4 pode ser encontrada em Sampaio (2010).

${ }^{9}$ Se uma necessidade tivesse sido citada nos três empreendimentos e a outra necessidade tivesse sido citada em apenas dois, por exemplo, havia, portanto, uma diferença de um empreendimento.

${ }^{10}$ Se uma necessidade tivesse sido citada nos três empreendimentos e a outra necessidade tivesse sido citada em apenas um, por exemplo, havia, portanto, uma diferença de dois empreendimentos. festas", quanto ao critério "citação", a primeira foi citada como necessidade insatisfatória em um empreendimento a mais do que a segunda. Por isso, o primeiro valor da segunda linha é 5; o contrário ocorre na situação inversa entre essas duas necessidades, que tem como primeiro valor da segunda coluna 0,2 . Os valores de " $\pi$ ", "P" e "p", por sua vez, resultaram das mesmas equações citadas anteriormente para a comparação entre os atributos (Equações 1, 2 e 3).

As demais comparações pareadas (critérios "justificativa" e "interferência") podem ser verificadas em Sampaio (2010).

Por fim, a última comparação realizada foi entre as necessidades insatisfatórias (alternativas) e os critérios (atributos), como é mostrado no Quadro 4. Os valores relativos às "prioridades do nível 2" dizem respeito aos valores de "p", para cada um dos critérios, alcançados na comparação entre os atributos (Quadro 2). Já os valores indicados nas três colunas (correspondentes à relação entre 0 critério e a necessidade), obtidos a partir das comparações pareadas entre as necessidades em função de cada critério, referem-se ao valor de " $p$ " de cada uma das três matrizes (aqui apresentado apenas o Quadro 3). Por último, o valor final de cada uma das necessidades, relativo à "composição de prioridades hierárquicas", foi alcançado através da Equação 4. Em relação ao salão de festas, por exemplo, a equação foi: $\mathrm{p}=(0,73 \times 0,00)+$ $(0,19 \times 0,382)+(0,08 \times 0,002)=0,07$.

Percebe-se que, devido à quantidade de necessidades insatisfatórias, foram obtidos valores nulos para a "composição de prioridades hierárquicas" em relação à metade das alternativas. Assim, os itens "iluminação externa", "segurança", "nível de ruído", "parede", "salão de festas" e "guarita" apresentaram, nessa ordem, maior prioridade de análise junto ao grupo focal.

138 Sampaio, J. C. S.; Silva e Romcy, N. M.; Sombra, P. L.; Barros Neto, J. de P. 


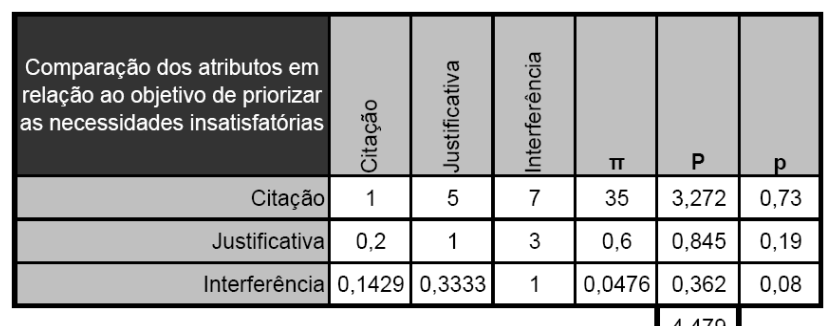

Quadro 2 - Comparação entre os atributos

Fonte: Sampaio (2010).

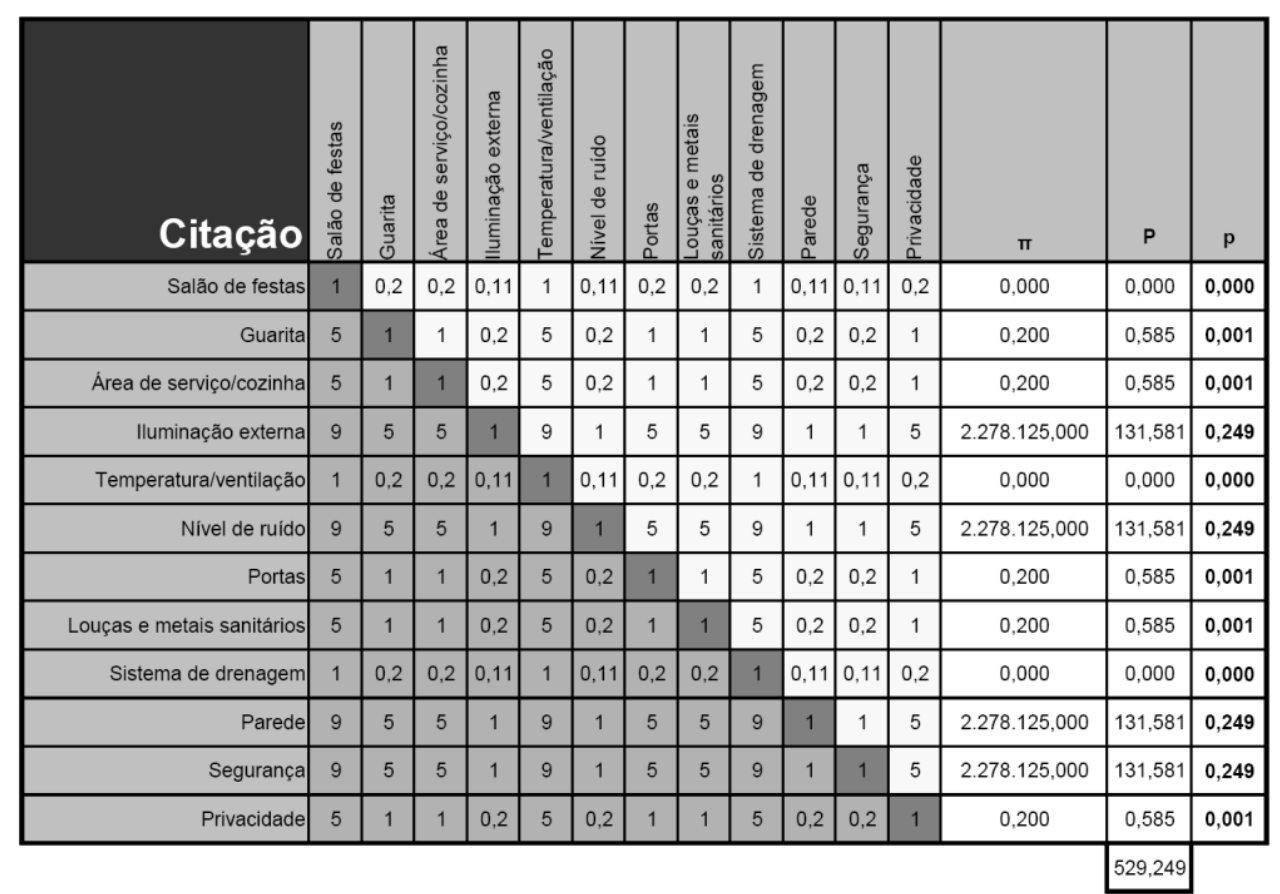

Quadro 3 - Comparação entre as necessidades em relação ao critério "citação"

Fonte: Sampaio (2010).

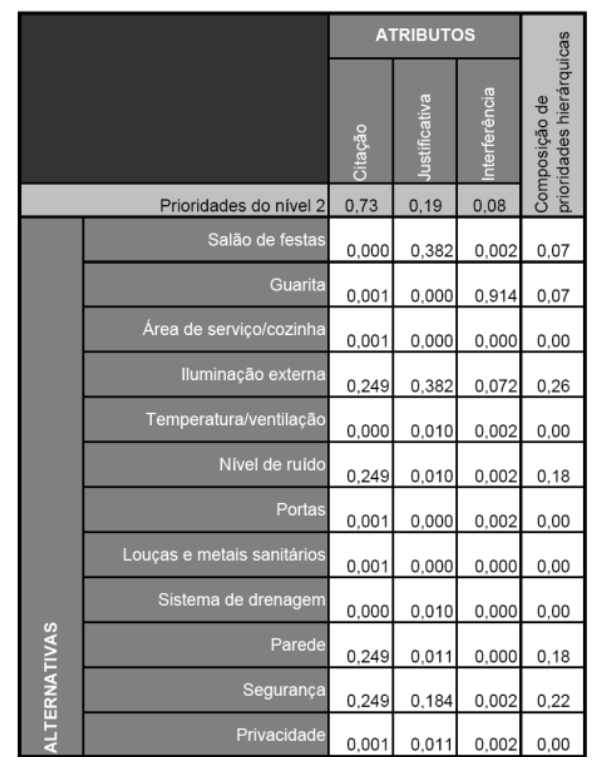

Quadro 4 - Comparação entre as necessidades (alternativas) e os critérios (atributos)

Fonte: Sampaio (2010). 
Destaca-se que, além da realização desses três primeiros passos, os formulários dos passos 4 e 5 foram preparados para a condução do grupo focal. Em relação ao primeiro deles, foram confeccionados seis formulários contendo a necessidade dos clientes e o requisito funcional relativo a ela (Figura 7). Quanto ao formulário da Casa da Qualidade (Figura 8), o quadrante relativo às necessidades dos clientes foi preenchido com as necessidades primárias, secundárias e terciárias resultantes do diagrama de afinidades.

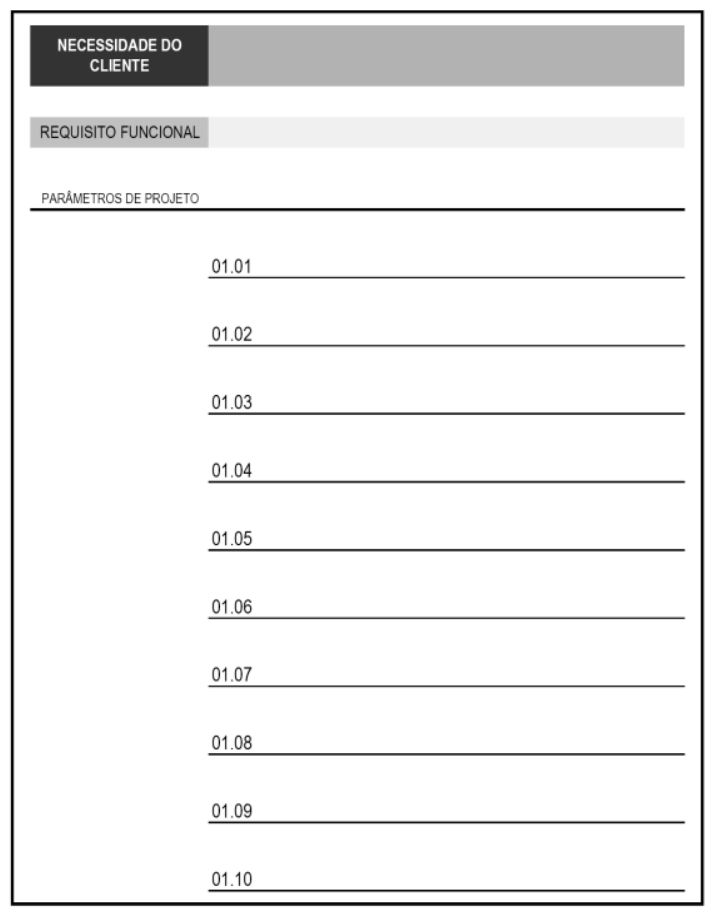

Figura 7 - Formulário de definição dos parâmetros de projeto

Fonte: Sampaio (2010).

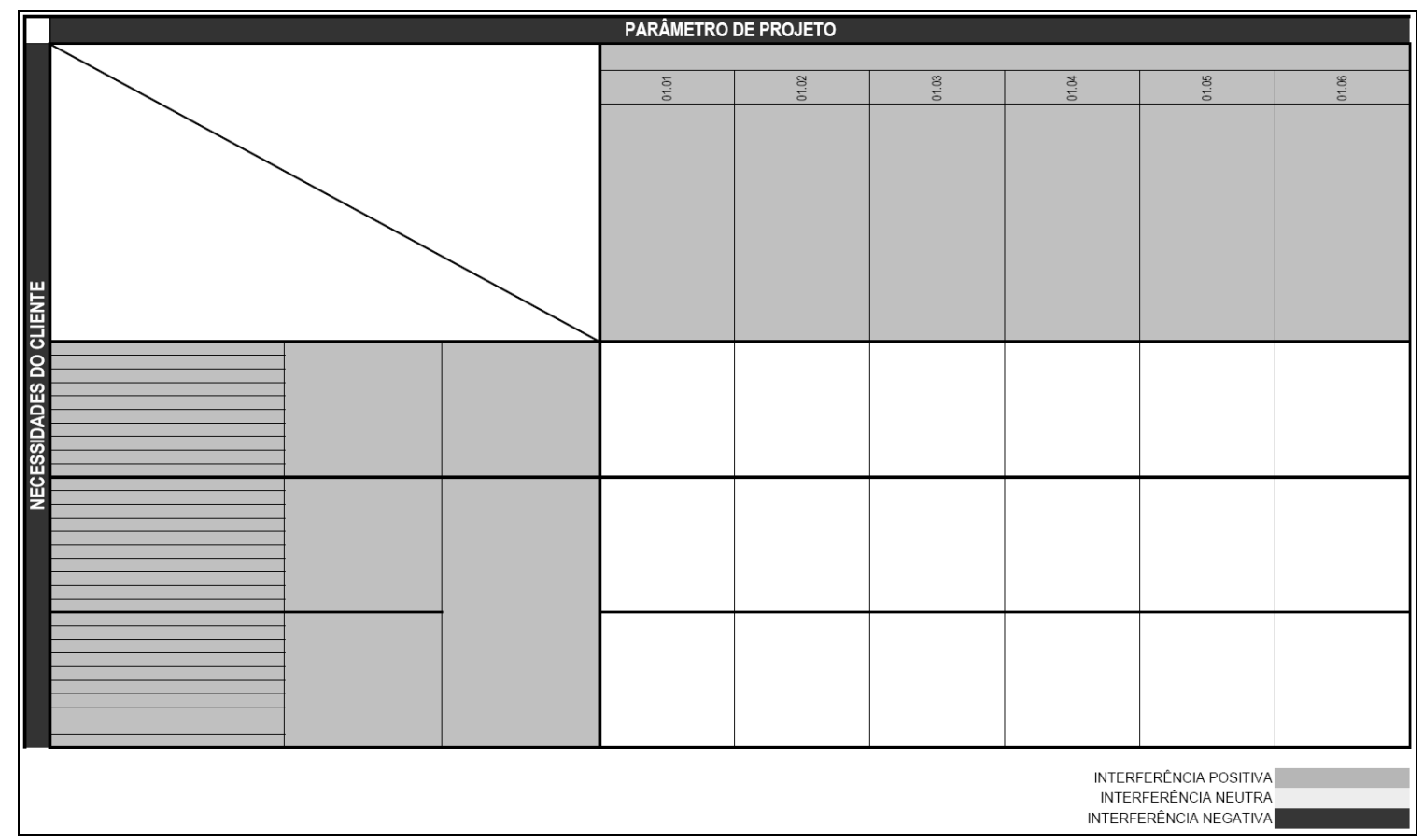

Figura 8 - Casa da Qualidade

Fonte: adaptado de Sampaio et al. (2009). 


\section{Transformação das necessidades insatisfatórias em parâmetros de projeto (Figura 9)}

Durante a aplicação do modelo, para cada um dos grupos foram designadas três necessidades insatisfatórias a serem discutidas. $\mathrm{O}$ grupo 1 analisou os itens "salão de festas", "segurança" e "nível de ruído"; o grupo 2 analisou "guarita/entrada do bloco", "iluminação externa" e "parede". Para cada uma desses itens, já haviam sido designados, pelos pesquisadores, os requisitos funcionais correspondentes. Estes representam aquilo que os clientes e os projetistas desejam. Já os parâmetros de projeto, definidos neste passo, representam como esses requisitos serão alcançados. As atividades 4 e 5, portanto, foram realizadas sequencialmente. Os moderadores, de posse dos formulários da atividade 4 (Figura 10), apresentaram para cada grupo a necessidade do cliente e o requisito funcional específico da necessidade analisada, bem como disponibilizaram alguns trechos do relatório da avaliação de satisfação com as respectivas justificativas. $\mathrm{O}$ grupo, então, discutiu acerca dos parâmetros de projeto que poderiam gerar maior satisfação para os moradores e, no momento em que era estabelecido um consenso, o formulário era preenchido.

\section{Avaliação das interferências entre as necessidades dos clientes e os parâmetros de projeto (Figura 11)}

Uma vez que as sugestões de parâmetros de projeto estivessem finalizadas, a Casa da Qualidade, o formulário da atividade 5 (Figura 12) era completado. Os profissionais verificavam as interferências existentes entre as necessidades dos clientes e os parâmetros de projeto. Aquelas que fossem consideradas positivas eram pintadas de verde; as neutras, de amarelo; e as negativas, de vermelho.

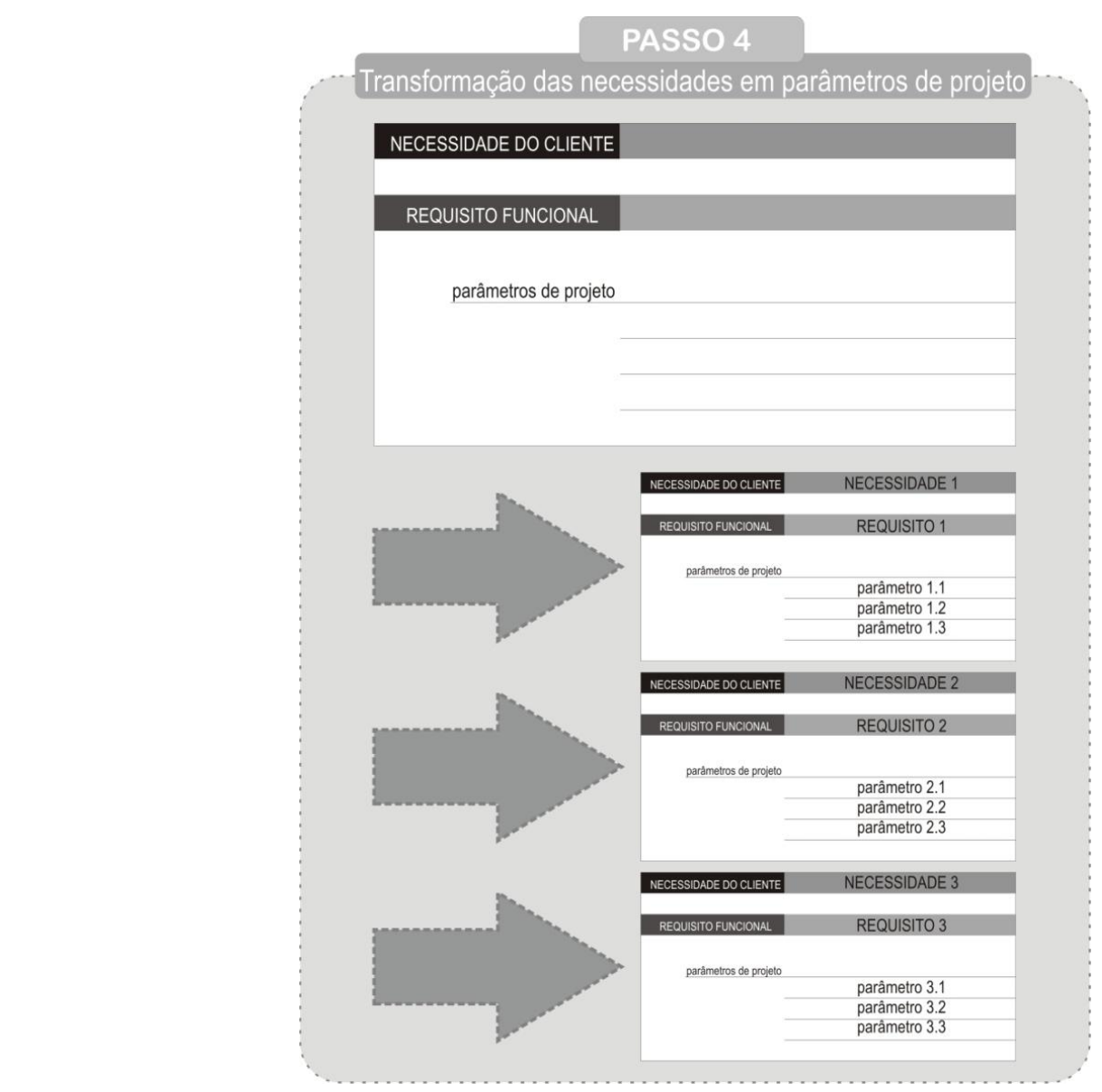

Figura 9 - Passo 4 do modelo teórico

Fonte: Sampaio (2010). 


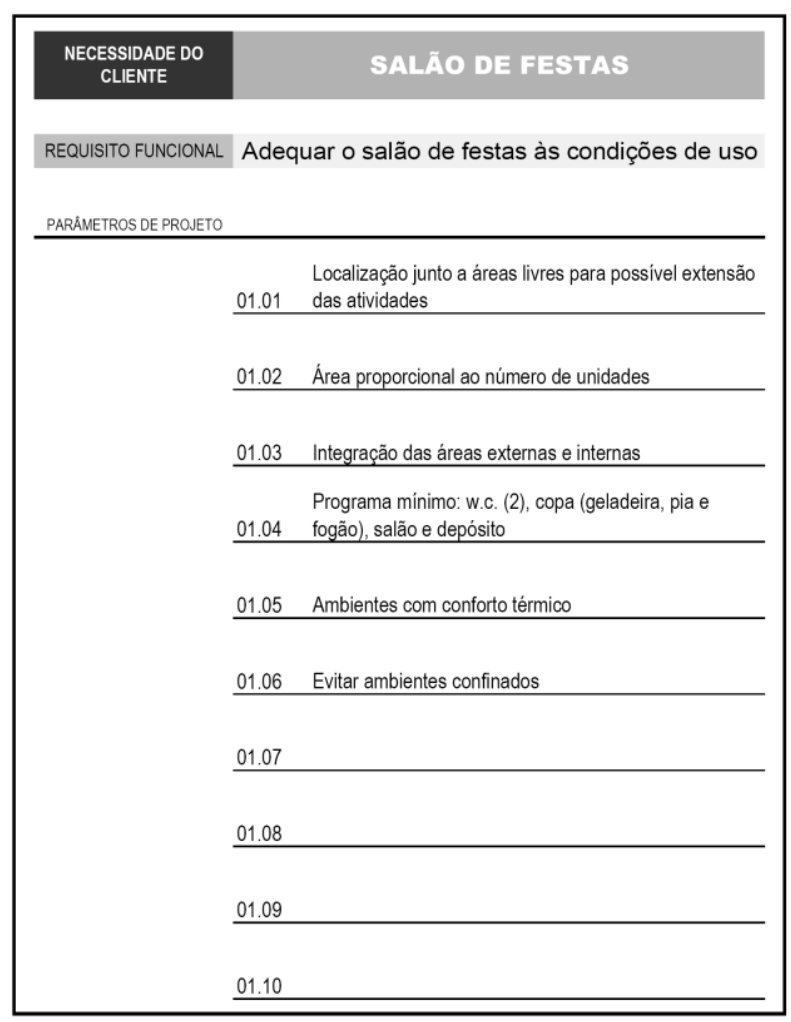

Figura 10 - Formulário do salão de festas

Fonte: Sampaio (2010).

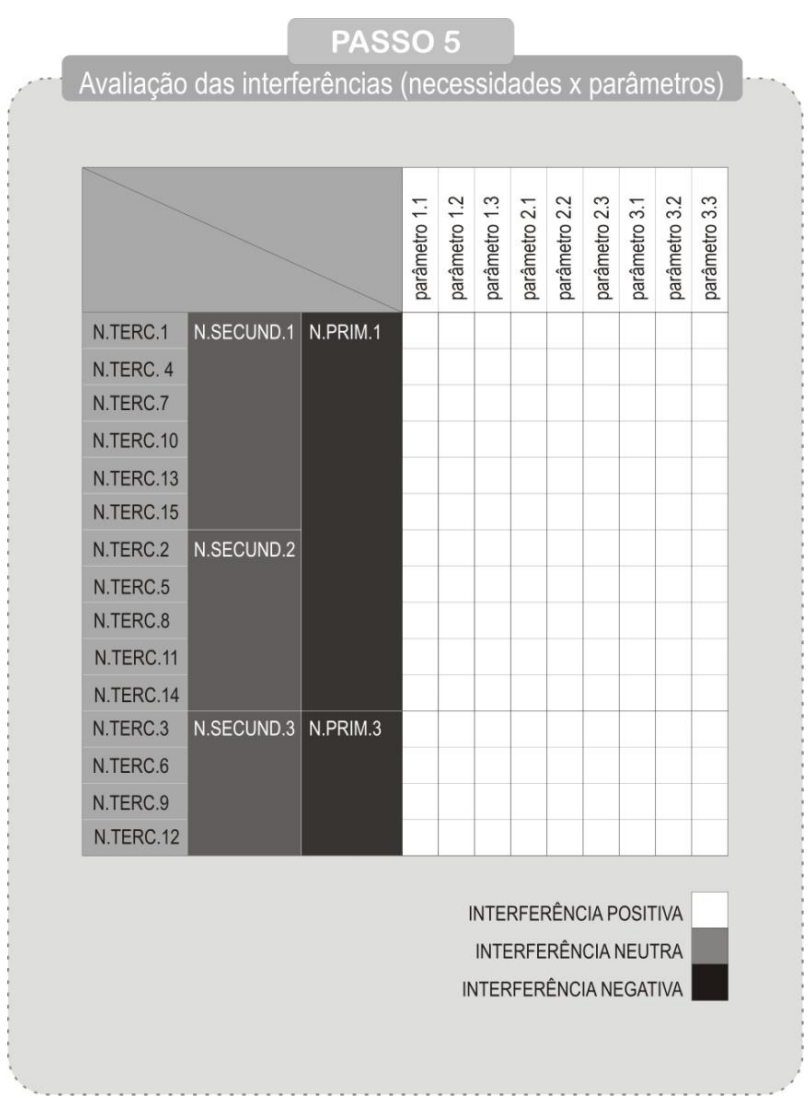

Figura 11 - Passo 5 do modelo teórico

Fonte: Sampaio (2010).

142 Sampaio, J. C. S.; Silva e Romcy, N. M.; Sombra, P. L.; Barros Neto, J. de P. 


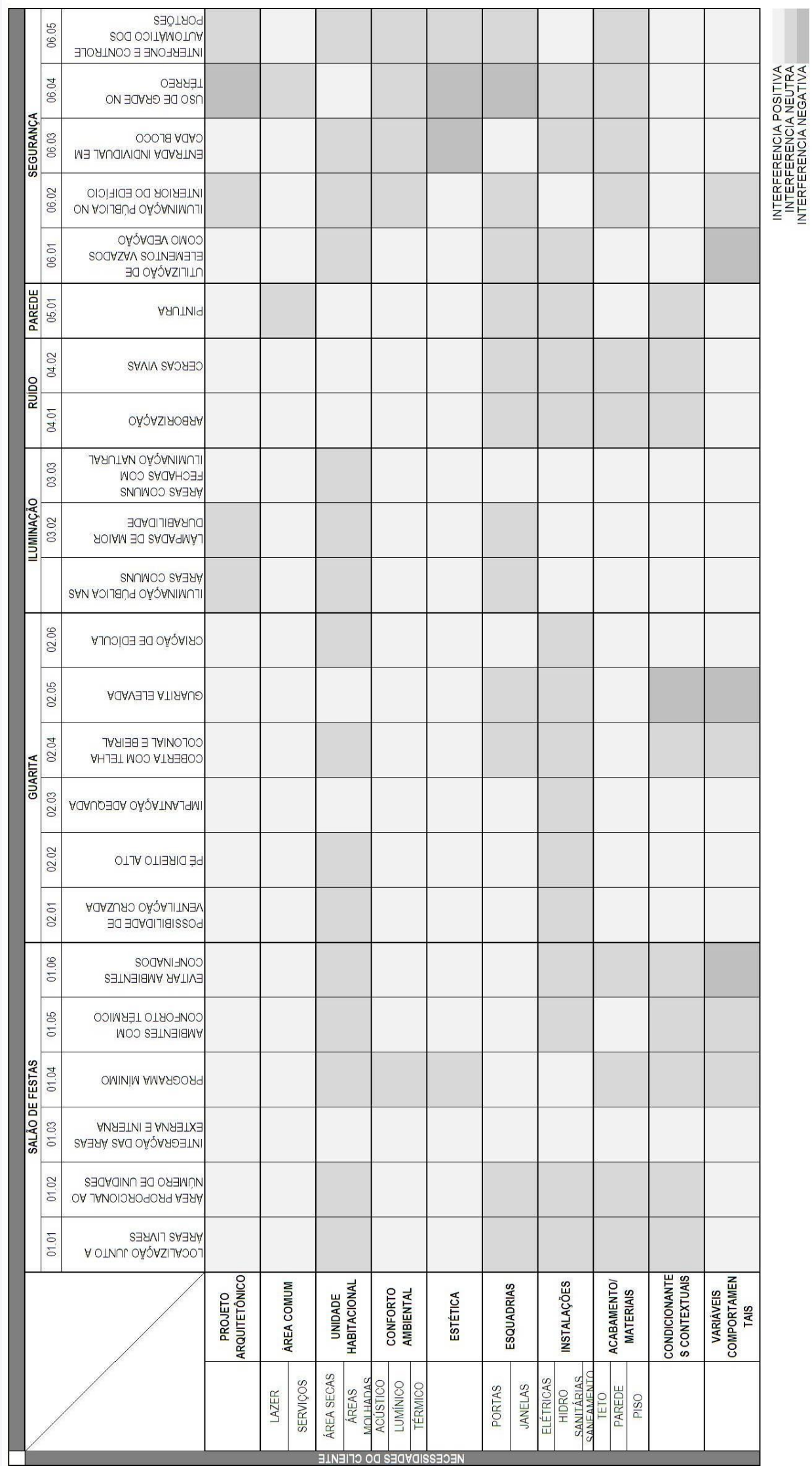

Figura 12 - Formulário da Casa da Qualidade

Fonte: adaptado de Sampaio (2010). 


\section{Análise da segunda versão do modelo}

Os dados provenientes desta discussão foram categorizados em seis grupos, os quais foram pontualmente analisados:

(a) processo de aplicação do modelo;

(b) importância do modelo;

(c) abrangência do modelo;

(d) parâmetros de projeto;

(e) atores envolvidos no PDP; e

(f) retroalimentação.

Em termos gerais, constatou-se que esta versão do modelo pode ser considerada como passível de ajudar a gerar mais valor para os moradores de empreendimentos habitacionais públicos. Faz-se necessário, porém, averiguar a aplicabilidade do modelo em outros contextos. Além disso, embora o modelo tenha sido considerado bom e tenha evidenciado o parâmetro da qualidade, mostrou-se deficiente na consideração do aspecto financeiro.

Já em relação à aplicação do modelo, verificou-se que se deve atentar para os critérios eleitos para a priorização das necessidades insatisfatórias. Destacou-se, durante o grupo focal, que algumas dessas necessidades não eram relativas ao projeto arquitetônico propriamente dito. Elas existiam no rol de insatisfações (e.g., área de serviço/cozinha), mas não estava explícito o motivo de terem sido consideradas insatisfatórias. Essa questão aponta para a utilização de questionários que tentem detectar mais detalhadamente a causa de as necessidades serem consideradas insatisfatórias.

Quanto às questões levantadas acerca das diferentes opiniões dos atores envolvidos no PDP, o modelo vem contribuir para o estabelecimento de um consenso, embora não seja fácil alcançá-lo. Faz-se importante relembrar que um dos aspectos positivos das ferramentas é a formação de equipes multidisciplinares, a qual foi buscada na realização do grupo focal. Portanto, a discussão entre os diversos atores é uma prerrogativa do modelo.

Finalmente, a importância da retroalimentação, salientada pelos participantes do grupo focal, reforça a necessidade de pesquisas que contribuam para esse fim, como a proposição de um modelo que auxilie nesse processo.

\section{Terceira versão do modelo}

Após o grupo focal, a última versão do modelo foi proposta (Figura 13).

No passo 1, as necessidades dos clientes são definidas a partir dos resultados de avaliações de satisfação realizadas em edificações com tipologia similar ao novo edifício planejado. As necessidades são listadas, e o nível de satisfação é indicado. O critério de classificação das necessidades (insatisfatórias, neutras e satisfatórias) é definido, e elas são, então, classificadas.

No passo 2, as necessidades são desdobradas em primárias, secundárias e terciárias através do diagrama de afinidades. Todas as necessidades resultantes da avaliação de satisfação (necessidades terciárias) são escritas em cartões de dados coloridos (magenta para as necessidades insatisfatórias, amarelo para as neutras e verde para as satisfatórias). Os cartões são agrupados de acordo com as afinidades existentes entre eles, e, para cada grupo, um cartão de afinidade é incorporado (necessidades secundárias). Por último, todos os cartões são colados numa folha, e os grupos de afinidade são reunidos em grupos mais abrangentes (necessidades primárias).

No passo 3, as necessidades insatisfatórias são priorizadas com o auxílio do AHP. Os projetistas devem eleger quais serão os atributos de priorização. No primeiro nível da análise, os atributos são comparados entre si para verificar a relação entre eles. No segundo nível, as necessidades insatisfatórias são comparadas entre si em função de cada um dos atributos. Já no terceiro nível, as necessidades são comparadas com os atributos. O resultado define a priorização das necessidades.

No passo 4, as necessidades insatisfatórias são transformadas em parâmetros de projeto através de conceitos da AD. Para cada necessidade, um requisito funcional é estabelecido, o qual representa o que deve ser feito; já o parâmetro significa como isso deve ser realizado. A definição dos parâmetros ocorre através da indicação de soluções pelos projetistas e do estabelecimento de um consenso. Formulários específicos são preenchidos para cada necessidade (Figura 4). 


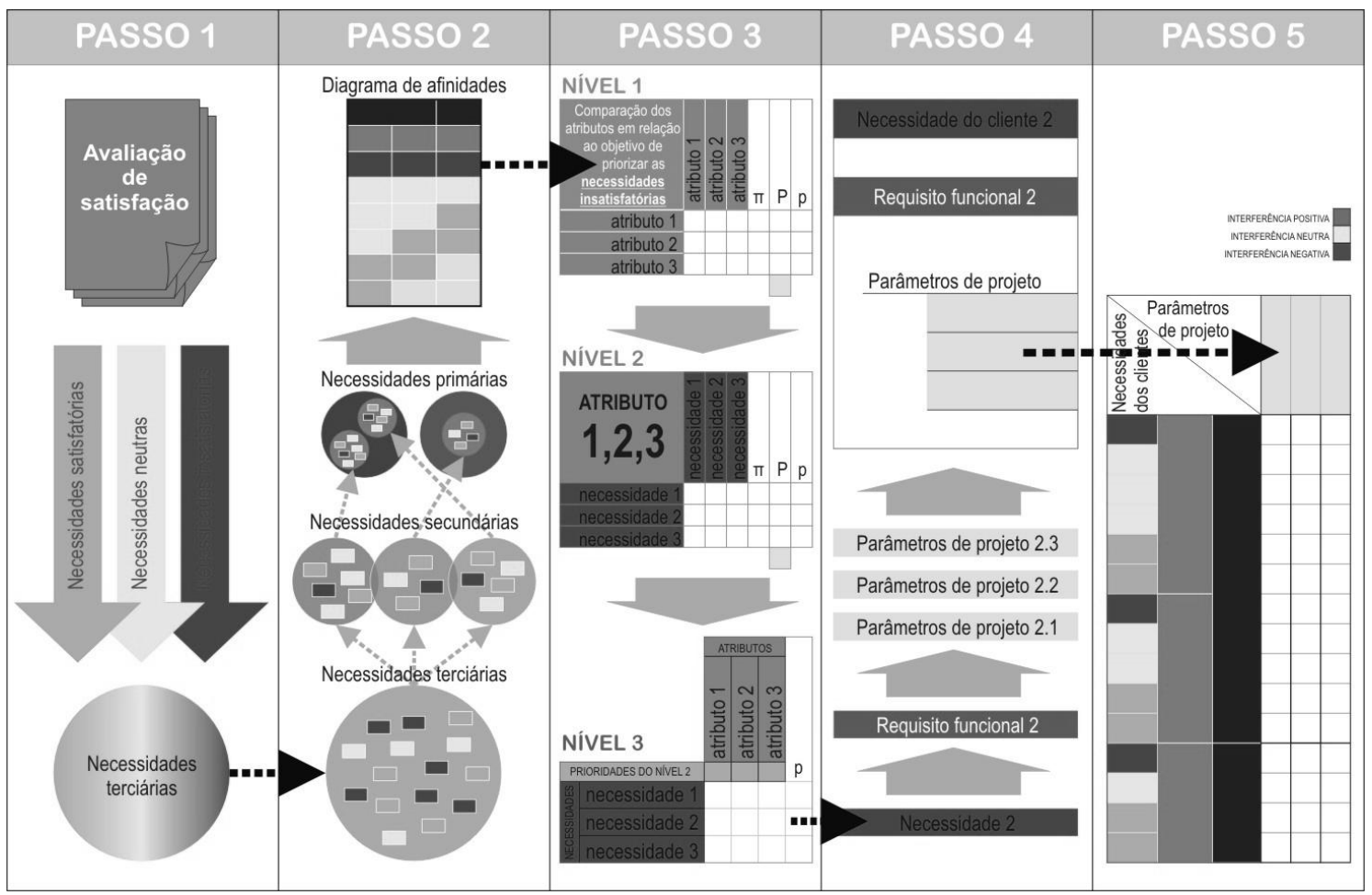

Figura 13 - Relação entre os cinco passos da terceira versão do modelo

Fonte: Sampaio (2010).

Finalmente, no passo $\mathbf{5}$, as interferências (positivas, negativas ou neutras) entre as necessidades dos clientes e os parâmetros de projeto são avaliadas através da Casa da Qualidade (QFD), a qual é preenchida com os parâmetros de projeto definidos no passo 4 e com as necessidades que compõem o diagrama de afinidade (passo 2), conforme pode ser visto na Figura 7.

\section{Teste do modelo}

A aplicação do modelo partiu de uma pesquisa de satisfação desenvolvida junto a moradores de dois empreendimentos imobiliários voltados para o público de classe média alta. Buscou-se, inicialmente, seguir os passos do modelo teórico, porém, conforme as dificuldades foram surgindo, algumas modificações foram propostas, a fim de aprimorar o modelo.

No passo 1, foi necessária uma adaptação dos critérios de classificação, devido ao fato de a pesquisa de satisfação não ter sido realizada visando à posterior aplicação do modelo. No caso da coleta, foi utilizado um questionário de satisfação versus importância, o qual abordou os diversos aspectos da moradia em um total de 33 itens. Cada item deveria ser avaliado pelo usuário, com uma nota de 0 a 10 , de acordo com seu nível de satisfação ${ }^{11}$ e seu nível de importância ${ }^{12}$. A partir desses dados, foram estabelecidas matrizes de satisfação versus importância (Figura 14), as quais estabeleceram a relação entre o nível de satisfação do cliente sobre determinado item e o grau de importância considerado por ele.

Para a classificação das necessidades dos clientes, consideraram-se essas matrizes de satisfação versus importância (uma para cada empreendimento), segundo os seguintes critérios:

(a) necessidades insatisfatórias: altas notas de importância e baixas notas de satisfação;

(b) necessidades satisfatórias: altas notas de importância e altas notas de satisfação; e

(c) necessidades neutras: baixas notas de importância, independentemente da nota de satisfação.

Essa classificação resultou em um total de 8 necessidades insatisfatórias, 25 necessidades satisfatórias e nenhuma necessidade neutra, visto que todas apresentaram altas notas de importância.

\footnotetext{
${ }^{11}$ As notas de satisfação traduzem a qualidade do produto ou serviço oferecido, cabendo à equipe de projetos fazer os ajustes necessários à análise.

${ }^{12}$ As notas de importância traduzem as expectativas que os clientes têm em relação ao determinado item, questão ou empreendimento, ou o quanto o mesmo é importante para a realização de suas atividades cotidianas.
} 


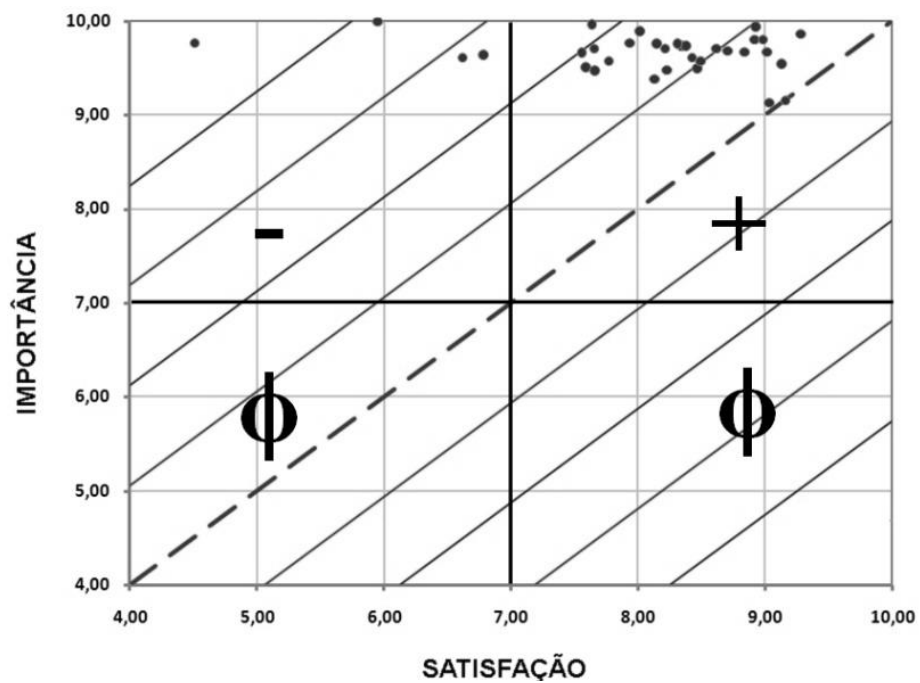

Figura 14 - Matriz de satisfação x importância do empreendimento A

Fonte: Adaptada da pesquisa de satisfação utilizada.

\begin{tabular}{|c|c|c|c|}
\hline EMPREENDIMENTO A & DELTA & EMPREENDIMENTO B & DELTA \\
\hline Nível de Ruído & $-5,3$ & Acesso ao Condomínio & $-3,7$ \\
\hline Fidelidades aos Prazos & -4 & Nível de Ruído & $-3,6$ \\
\hline Esquadrias & -3 & Segurança do Condomínio & $-3,5$ \\
\hline Cozinha / Área de Serviço & $-2,8$ & Guarita & $-3,4$ \\
\hline & & Complexo de Lazer & $-3,2$ \\
\hline & & Fidelidades aos Prazos & -3 \\
\hline
\end{tabular}

Quadro 5 - Lista de necessidades insatisfatórias, separadas por empreendimento, em ordem crescente de delta

Nos casos em que uma necessidade não apresentou a mesma classificação em ambos os empreendimentos, priorizou-se o caráter insatisfatório.

No passo 2, não houve alteração no modelo teórico. As necessidades terciárias foram escritas em cartões de dados e foram agrupadas de acordo com suas afinidades.

No passo 3, quando se buscou aplicar a ferramenta AHP para a priorização das necessidades insatisfatórias, foram observados aspectos negativos no que diz respeito ao consumo de tempo e ao aumento de complexidade do procedimento. Portanto, considerando-se que a fase de priorização deve estabelecer apenas a ordem de discussão das necessidades insatisfatórias, sem caráter eliminatório, percebeuse que a proposição de um procedimento mais simplificado permitiria uma otimização de tempo, a ser utilizado nas fases posteriores de avaliação, o que demanda um debate maior. Optou-se, portanto, pela substituição da ferramenta AHP por um novo critério de priorização, o valor do delta ${ }^{13}$ calculado na matriz satisfação versus importância (Quadro 5).

Segundo esse critério, os itens de valores mais negativos representam uma diferença maior entre o grau de importância e o nível de satisfação do cliente com determinado item, devendo ter, assim, maior prioridade para discussão. A repetição de um mesmo item como insatisfatório em ambos os empreendimentos também foi considerada no critério de priorização, visto que representa problemas reincidentes para os mesmos projetistas.

Assim, aqueles itens que apareceram em ambos os empreendimentos como insatisfatórios e com deltas entre os mais negativos tiveram os valores de seus deltas somados, gerando um valor ainda mais negativo, que confirma sua posição como itens críticos (Quadro 6).

\footnotetext{
${ }^{13} \mathrm{O}$ valor do delta é definido a partir da diferença entre a nota de satisfação e a nota de importância. Na pesquisa de satisfação utilizada, portanto, o delta foi adotado como um índice representativo na determinação da relação entre satisfação e importância de um item.
} 


\begin{tabular}{|c|c|}
\hline ORDEM GERAL & DELTA \\
\hline Nível de Ruído & $-8,9$ \\
\hline Fidelidades aos Prazos & $-7,6$ \\
\hline Acesso ao Condomínio & $-3,7$ \\
\hline Segurança do Condomínio & $-3,5$ \\
\hline Guarita & $-3,4$ \\
\hline Complexo de Lazer & $-3,2$ \\
\hline Esquadrias & -3 \\
\hline Cozinha / Área de Serviço & $-2,8$ \\
\hline
\end{tabular}

\section{Quadro 6 - Lista geral de necessidades insatisfatórias em ordem crescente de soma dos deltas}

No passo 4, devido à indisponibilidade da equipe da própria construtora responsável pelos empreendimentos, não foi possível a realização de uma reunião única com todos os projetistas envolvidos ${ }^{14}$. Dessa forma, o modelo foi aplicado em dois momentos distintos; primeiramente, com a equipe do escritório de arquitetura e, posteriormente, com a coordenadora de projetos da construtora.

A partir das necessidades insatisfatórias, foram estabelecidos os requisitos funcionais $\mathrm{e}$, posteriormente, os parâmetros de projeto; os formulários relativos a esse passo foram preenchidos. Ao longo da discussão de cada necessidade insatisfatória, surgiu a necessidade de incluir, ainda, um campo contendo observações adicionais e relevantes trazidas pelos projetistas.

No passo 5, foi realizado o preenchimento da Casa da Qualidade. Assim como no passo 2, não houve alteração em relação ao modelo teórico.

A principal modificação no modelo teórico, portanto, foi a substituição da ferramenta AHP pela matriz satisfação versus importância, o que simplificou o processo de aplicação dos primeiros passos do modelo. Deve-se salientar que, a partir da consideração das dificuldades práticas por parte dos projetistas (e.g., demanda de tempo, falta de familiaridade com as ferramentas), essa simplificação do modelo torna-se importante para sua viabilidade.

Ressalta-se, ainda, que esse teste veio reiterar a importância do modelo para o processo de retroalimentação do projeto, pois, segundo o arquiteto responsável pelo escritório consultado, "[...] permite um feedback importante, ao qual os arquitetos não costumam ter acesso, por falta de comunicação direta com os usuários, normalmente realizada pelos corretores.”.

$14 \mathrm{Em}$ ambos os empreendimentos, a construtora responsável contou com a parceria de um escritório de arquitetura particular, além da participação de sua própria equipe.

\section{Considerações finais}

Esta pesquisa foi iniciada com a verificação da ausência de um processamento sistemático dos dados coletados em avaliações de satisfação de forma a subsidiar o processo de projeto. Isso foi verificado a partir da constatação de que os resultados das avaliações são repassados informalmente. Porém, torna-se importante que esses dados sejam utilizados sistematicamente no processo de novos projetos, a fim de possibilitar aos empreendimentos futuros maior satisfação dos clientes.

Verifica-se que a sequência projeto-construção-uso não deve ser um procedimento linear, que se inicia em um ponto e termina em outro, mas um ciclo contínuo, sendo a etapa do projeto retroalimentada pela de uso. A geração de valor não se esgota em uma sequência única, mas se aprimora mediante novas experiências. Uma vez que a retroalimentação tenha-se tornado uma prática realizada pelo incorporador, os clientes finais tendem a se satisfazer mais. A busca pela melhoria contínua, portanto, deve-se tornar um objetivo precípuo desses incorporadores.

A pesquisa alcançou o objetivo, já que busca inserir a retroalimentação no processo de projeto através da criação do modelo, como demonstra a criação de um check list a partir dos parâmetros de projeto, o que facilita a transferência de dados.

A aplicação prática do modelo, contudo, demonstrou a necessária adaptação de acordo com a avaliação de satisfação utilizada, visto que os instrumentos não foram elaborados para uma posterior utilização junto a esse modelo de retroalimentação. $\mathrm{O}$ ideal seria que as pesquisas de satisfação futuras fossem realizadas tendo como um de seus objetivos a retroalimentação do processo de projeto, o que se configura como uma possibilidade de pesquisa nessa área.

Em relação às contribuições acadêmicas, esta pesquisa discorre sobre a possibilidade de uma retroalimentação sistematizada do processo de 
projeto a partir dos dados provenientes de avaliações de satisfação, assunto pouco abordado na literatura. Por último, o modelo proposto pode ser utilizado, na prática, por empresas interessadas em se valer de avaliações de satisfação para retroalimentar o processo de novos projetos com características tipológicas similares, o que se constitui como uma contribuição de ordem técnica.

O modelo teórico, portanto, buscou facilitar o processamento das informações advindas de avaliações de satisfação, realizadas para empreendimentos da indústria da construção civil, tendo em vista a facilitação de uso de seus resultados por parte dos projetistas responsáveis pela concepção de tais empreendimentos, retroalimentando essa cadeia produtiva e possibilitando a geração de valor para o usuário final.

\section{Referências}

CARVALHO, M. A.; BACK, N. Uso dos Conceitos Fundamentais da Triz e do Método dos Princípios Inventivos no Desenvolvimento de Produtos. In: CONGRESSO BRASILEIRO DE GESTÃO DE DESENVOLVIMENTO DE PRODUTO, 3., Florianópolis, 2001. Anais... Florianópolis, 2001.

CARVALHO, M. T. M.; SPOSTO, R. M. Aplicação da Ferramenta Processo de Análise Hierárquica (AHP) para Determinação de Critérios Essenciais para Projetos Sustentáveis de Habitações de Interesse Social (HIS) na Cidade de Goiânia, GO. In: ENCONTRO LATINOAMERICANO SOBRE EDIFICAÇÕES E COMUNIDADES SUSTENTÁVEIS, 2., Goiás, 2007. Anais... Goiás: ANTAC, 2007. p. 353-362.

DELGADO-HERNANDEZ, D. J., BAMPTON, K. E.; ASPINWALL, E. Quality Function Deployment in Construction. Construction Management and Economics, v. 25, n. 6, p. 597609, jun. 2007.

EGEMEN, M., MOHAMED, A. N. Client` Needs, Wants and Expectations from Contractors and Approach to the Concept of Repetitive Works in the Northern Cyprus Construction Market. Building and Environment, v. 41, n. 5, p. 602614, 2006.

EUREKA, W. E.; RYAN, N. E. QFD: perspectivas gerenciais do desdobramento da função qualidade. Rio de Janeiro: Qualitymark, 1992. $105 \mathrm{p}$.

GASS, S. Decision Making, Models and Algorithms: a first course. Nova York: Wiley Interscience, 1985.
GERENCIAMENTO DE REQUISITOS E MELHORIA DA QUALIDADE NA HABITAÇÃO DE INTERESSE SOCIAL. REQUALI. Disponível em: <http://www6.ufrgs.br/norie/requali/>. Acesso em 5 dez. 2011.

KÄRNA, S.; JUNNONEN, J. M. Project Feedback as a Tool for Learning. In: ANNUAL CONFERENCE OF THE INTERNATIONAL GROUP FOR LEAN ONSTRUCTION, 13., Sydney, 2005. Anais... Sydney, 2005. p. 47-55.

KOSKELA, L.; HUOVILA, P.; LEINONEN, J. Design Management in Building Construction: from theory to practice. Journal of Construction Research, v. 3, n. 1, p. 1-16, 2002.

LIMA, M. M. X., Análise de Inadequações Projetuais do Setor Serviço Sob a Ótica da Geração de Valor para o Usuário em Habitações de Iinteresse Social. 2011. 260 f. Dissertação (Mestrado em Engenharia Civil) Centro de Tecnologia, Universidade Federal do Ceará, Fortaleza, 2011.

MAIA, S. C., LIMA, M. M. X., BARROS NETO, J. de P. A Systemic Approach to the Concept of Value and Its Effects on Lean Construction. In: INTERNATIONAL GROUP OF LEAN CONSTRUCTION CONFERENCE, 4., Vitória, 2011. Proceedings... Vitória, 2011.

MELHADO, S. B.; AGOPYAN, V. O Conceito de Projeto na Construção de Edifícios: diretrizes para sua elaboração e controle. In: DEPARTAMENTO DE ENGENHARIA DE CONSTRUÇÃO CIVIL. Boletim Técnico da Escola Politécnica da USP. São Paulo: EPUSP, 1995. 20 p.

MONICE, S.; PETRECHE, J. R. D. Projeto Axiomático de Arquitetura: estudo para implantação em sistemas CAD. In: DEPARTAMENTO DE ENGENHARIA DE CONSTRUÇÃO CIVIL. Boletim Técnico da Escola Politécnica da USP. São Paulo: EPUSP, 2004. 20p.

MOREIRA, D. C.; KOWALTOWSKI, D. C. C. K. Discussão Sobre a Importância do Programa de Necessidades no Processo de Projeto em Arquitetura. Ambiente Construído, Porto Alegre, v. 9, n. 2, p. 31-45, abr./jun. 2009.

ORNSTEIN, S. W. APO e a Gestão da Qualidade no Processo de Projeto. In: ENCONTRO

NACIONAL DE TECNOLOGIA DO AMBIENTE CONSTRUÍDO, 12., Fortaleza, 2008. Anais... Fortaleza: ANTAC, 2008.

148 Sampaio, J. C. S.; Silva e Romcy, N. M.; Sombra, P. L.; Barros Neto, J. de P. 
SAMPAIO, J. C. S. Proposição de Um Modelo de Retroalimentação da Gestão do Processo de Projeto a Partir de Medições de Satisfação de Clientes. 188 f. Fortaleza 2010. Dissertação (Mestrado em Engenharia Civil) - Programa de Pós-Graduação em Engenharia Civil, Universidade Federal do Ceará, Fortaleza, 2010.

SAMPAIO, J. C. S. et al. O Uso de Dados Provenientes de Pesquisas de Satisfação para Análise com QFD. In: SIMPÓSIO BRASILEIRO DE GESTÃO E ECONOMIA DA CONSTRUÇÃO, 6., João Pessoa, 2009. Anais... João Pessoa: ANTAC, 2009.

SAMPAIO, J. C. S.; LIMA, M. M. X.; BARROS NETO, J. de P. A Utilização de Ferramentas de Apoio à Tomada de Decisão no Processo de Projeto. Gestão e Tecnologia de Projetos, São Carlos, v. 5, n. 1, p. 56-78, jul. 2010.

TANG, S. L.; LU, M.; CHAN, Y. L. Achieving Client Satisfaction for Engineering Consulting Firms. Journal of Management in Engineering, v. 19 , n. 4 , p. 166-172, out. 2004.
TILLEY, P. A. Lean Design Management: a new paradigm for managing the design and documentation process to improve quality? In: ANNUAL CONFERENCE OF THE INTERNATIONAL GROUP FOR LEAN CONSTRUCTION, 13., Sydney, 2005. Anais... Sydney, 2005. p. 283-295.

WHELTON, M.; BALLARD, G. Project Definition and Wicked Problems. In: ANNUAL CONFERENCE OF THE INTERNATIONAL GROUP FOR LEAN CONSTRUCTION, 10. 2002, Gramado. Anais... Gramado, 2002. p. 375387.

YANG, K.; ZHANG, H. A Comparison of Triz and Axiomatic Design. In: INTERNATIONAL CONFERENCE ON AXIOMATIC DESIGN, 1. Cambridge, 2000. Anais... Cambridge, 2000. p. 235-242.

\section{Agradecimentos}

Os autores agradecem aos arquitetos e engenheiros civis que participaram do grupo focal, à empresa construtora e ao escritório de arquitetura que participaram do teste do modelo, e ao Conselho Nacional de Desenvolvimento Científico e Tecnológico (CNPq).

Revista Ambiente Construído

Associação Nacional de Tecnologia do Ambiente Construído

Av. Osvaldo Aranha, 99 - $3^{\circ}$ andar, Centro

Porto Alegre - RS - Brasil CEP $90035-190$

Telefone: +55 (51) 3308-4084

Fax: +55 (51) 3308-4054

www.seer.ufrgs.br/ambienteconstruido

E-mail: ambienteconstruido@ufrgs.br 